\title{
Mortalidad Fetal en las Toxemias
}

Doctores: Alfonso Gutiérrez, Ernesto Sabogal y Julio Sánchez.

Considerada la estadistica de los últimos once años del Instituto, es posible extraer algunos datos sobre la mortalidad de los hijos de las mujeres afectadas por toxemias gravidicas, que tienen importancia para el estudio del pronóstico. y del tratamiento que se haya de seguir en tales casos desde el punto de vista pediátrico. lo que combinado con el criterio puramente obstétrico, que considera primordialmente a la madre, puede llevar a conclusión favorable para ambos.

El resumen estadistico en cuanto a la mortalidad fetal, es el siguiente:

\begin{tabular}{|c|c|c|c|c|c|c|}
\hline \multirow[t]{2}{*}{150} & \multicolumn{2}{|c|}{ ALBLMINURIA } & \multicolumn{2}{|c|}{ PREECLAMPSIA } & \multicolumn{2}{|c|}{ ECLAMPSIA } \\
\hline & Casos & & & & Casos: & Muertes: \\
\hline 942 & 0 & 0 & 11 & 2 & 42 & 19 \\
\hline 1943 & 20 & 4 & 7 & 3 & 41 & 20 \\
\hline 1944 & 2 & 1 & 27 & 6 & 43 & 22 \\
\hline 1945 & $\theta$ & 1 & 4 & 3 & 32 & 14 \\
\hline 1946 & 17 & 4 & 18 & 3 & 29 & 17 \\
\hline 1947 & 1 & 0 & 52 & 7 & 28 & 8 \\
\hline 1948 & 13 & 0 & 94 & 0 & 33 & 17 \\
\hline 1949 & 3 & 2 & 144 & 20 & 49 & 24 \\
\hline 1950 & 18 & 3 & 44 & 10 & 54 & 26 \\
\hline 1951 & 52 & 5 & 53 & 2 & 11 & 4 \\
\hline 852 & 2 & 0 & 168 & 7 & 53 & 12 \\
\hline otales & 137 & 20 & 622 & 63 & 415 & 183 \\
\hline
\end{tabular}

En cuanto a la mortalidad en relación con determinado tipo de toxemia tiene el siguiente indice.

Indice general de mortalidad fetal en las toxemias .......... $22.6 \%$

Indice general de mortalidad fetal en las albuminurias... . . . . . 14.5\%

Indice general de mortalidad fetal en las preeclampsias........ 10.1\%

Indice general de mortalidad fetal en las eclampsias . . . . . . . $44.0 \%$

Lo primero que salta a la vista al considerar el cuadro anterior, es el elevadu mice de mortalidad del producto de lo que es atribuíble a tres causas principales:

a) Intoxicación del feto, inherente al estado de toxemia materna, la cual bien puede causar la muerte por si misma, o bien lo pone en condiciones de menor re$\therefore$ istencia, haciéndolo más sensible a las diferentes afecciones y accidentes, propias cel parto y de las primeras horas de la vida; 
b) La prematurez o por mejor decir, inmadurez de tales niños, pues la estadis tica general del servicio hace ver que el promedio del peso es inferior a 2.500 gramos, habiendo que considerarlos como prematuros, aunque cronológicamente no lo sean, y por lo tanto, teniendo en cuenta los peligros y fragiliaad orgánicos propios de tal estado;

c) Como los datos tomados en consideración provienen de las pacientes aten didas en el Instituto, cuya gran mayoría pertenecen a la más baja capa social y económica, es necesario añadir el déficit fisiológico que la miseria, la avitaminosis y la desnutrición general materna producen en el feto.

En cuanto a la mortalidad en relación con determinado tipo de toxemia, es evidente de que la mayor corresponde a la eclampsia propiamente dicha (44\%), 10 que se explica por la mayor gravedad de esta afección y su mayor incidencia sobre la salud fetal. En cambio se encuentra un indice inferior para la preeclampsia $(10.1 \%)$, que para albuminuria simple $(14.5 \%)$; hecho en cierto modo contradictorio y que se explica por dos causas:

1.-Mayor frecuencia de tratamientos quirúrgicos y obstétricos en la preeclampsia que en la albuminuria, siendo aceptado por algunos en relación con el peso que es más ventajosa la intervención activa.

$2^{\text {a }}$-Diferencias de criterio sobre las dos entidades, que en muchos casos los que unos consideran como preeclampsia, otros la califican como simple albuminuria y viceversa.

\section{Causas de esta mortalidad}

No estando establecida la autopsia rutinaria de los niños muertos en estas condiciones y siendo en muchos casos deficientes los datos consignados en las historias es dificil discriminar exactamente las causas de muerte fetal, pero de una maner: general se puede establecer la siguiente tabla:

Mortinatos . ................................... $50 \%$

Asfixia y anoxia cerebral pocos minutos $u$ horas después del naci-

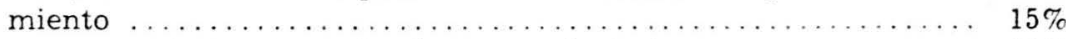

Bronconeumonía y otras afecciones respiratorias ............ $15 \%$

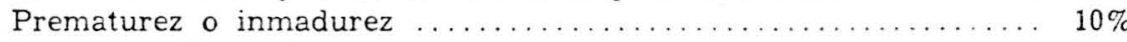

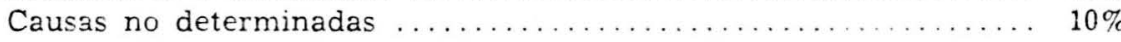

De las anteriores consideraciones se pueden sacar las siguientes conclusiones:

a) Importancia de la intensificación máxima de la vigilancia prenatal, para localizar desde el comienzo las toxemias gravídicas, y someter a las pacientes a un tratamiento adecuado por todo el tiempo que sea necesaric incluyendo controles de laboratorio frecuentes y regimenes alimenticios apropiados: uno de cuyos principales resultados sería la reducción de la cifra de mortinatos;

b) En los casos de eclampsia y preeclampsia siempre que exista la indicación de orden materno, preferir los tratamientos quirúrgicos y obstétricos que parecen más benéficos para el feto;

c) Importancia de la atención médica especial de los recién nac:dos, hijos de mujeres toxémicas. los que en su mayoria deben considerarse como prematuros y propensos a las complicaciones propias de este estado. 